\title{
Covert clues: the non-hallmark cutaneous manifestations of dermatomyositis
}

\author{
Rochelle L. Castillo ${ }^{1}$, Alisa N. Femia ${ }^{2}$ \\ ${ }^{1}$ Department of Medicine, Division of Rheumatology, NYU Grossman School of Medicine, New York, NY, USA; ${ }^{2}$ Ronald O. Perelman Department \\ of Dermatology, NYU Grossman School of Medicine, New York, NY, USA \\ Contributions: (I) Conception and design: All authors; (II) Administrative support: None; (III) Provision of study materials or patients: All authors; \\ (IV) Collection and assembly of data: RL Castillo; (V) Data analysis and interpretation: All authors; (VI) Manuscript writing: All authors; (VII) Final \\ approval of manuscript: All authors. \\ Correspondence to: Alisa N. Femia, MD. Ronald O. Perelman Department of Dermatology, New York University Langone Medical Center, 240 E \\ 38th St, 11th Floor, New York, NY 10016, USA. Email: alisa.femia@nyulangone.org.
}

\begin{abstract}
Dermatomyositis (DM) is a strikingly heterogenous disease characterized by a broad and everevolving spectrum of cutaneous manifestations that transcend the classic "hallmarks" defined by Peter and Bohan in 1975. Despite the increasing preponderance and ubiquity of autoantibody, radiologic, and electrophysiologic testing, the diagnosis of DM still hinges largely on prompt detection of cutaneous manifestations of this condition. While pathognomonic cutaneous features of DM are more readily recognizable, many patients present with subtle and/or atypical skin manifestations, and diagnosis of DM may require clinician identification of these cutaneous clues. In this review, we highlight several of the lesserknown skin manifestations of DM, specifically, panniculitis, diffuse subcutaneous edema, erythroderma, calcinosis, ulceration, flagellate erythema, Wong-type DM, gingival telangiectasias, and the ovoid palatal patch. We describe the clinical and histopathologic presentation of these cutaneous findings. While manifesting less frequently than the heliotrope rash, Gottron's papules, and Gottron's sign, these cutaneous clues are equally important for clinicians to recognize in order to facilitate timely diagnosis and early intervention.
\end{abstract}

Keywords: Skin; cutaneous; myositis; dermatomyositis (DM)

Submitted Jul 11, 2020. Accepted for publication Nov 10, 2020.

doi: $10.21037 /$ atm-20-5252

View this article at: http://dx.doi.org/10.21037/atm-20-5252

The presence of pathognomonic skin findings that are readily recognized by healthcare providers across the range of medical specialties has given dermatomyositis (DM) a unique diagnostic advantage over the other idiopathic inflammatory myopathies. From Peter and Bohan in 1975 to the EULAR/ACR classification criteria of 2016, the heliotrope rash, Gottron's papules, and Gottron's sign have endured as the indisputable cutaneous hallmarks of DM $(1,2)$. However; over the years, a myriad of other skin manifestations with varying degrees of specificity have emerged as characteristic clues to diagnosing DM, leading to further expansion of the known DM phenotype. Further, in a subset of DM patients, sparing of the muscles has been observed, prompting Sontheimer to propose the term "clinically amyopathic DM" to refer to DM patients with neither clinical nor serologic, electrophysiologic, or radiologic evidence of muscle involvement (amyopathic $\mathrm{DM}$ ) or those with findings of myopathy on work-up but no overt clinical disease (hypomyopathic DM) (3-5).

In recognition of this evolving heterogeneity, the Skin

$\wedge$ ORCID: 0000-0002-1704-9420. 
Table 1 List of 25 potential dermatomyositis classification criteria divided into categories of distribution, morphology, symptomatology, pathology and contextual factors proposed by the Skin Myositis Delphi Group (6)

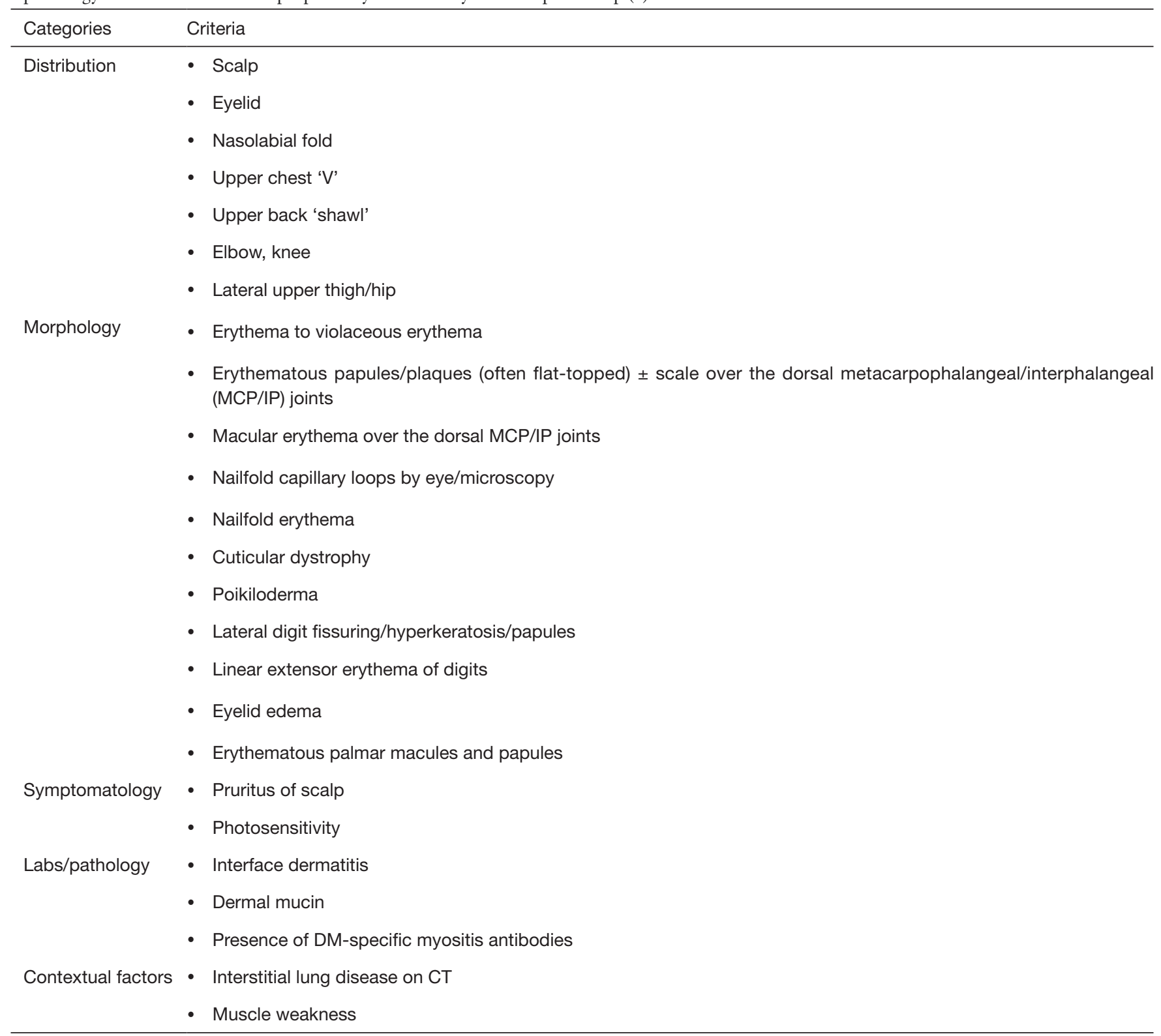

Myositis Delphi Group consisting of 50 dermatologists and rheumatologists from North America, South America, Europe, and Asia identified and proposed 25 items that could be incorporated into a more encompassing and comprehensive classification criteria for skin-predominant disease (Table 1) (6). These items could potentially expand the definition for what constitutes a "hallmark" cutaneous manifestation and subsequently facilitate early diagnosis and treatment, which is particularly critical in the subgroup of patients with skin-limited disease. Validation studies are currently in progress.

For the purposes of this review, we present several less common cutaneous findings of DM that, while relatively rare, are equally important to recognize in order to facilitate timely diagnosis and management of DM.

\section{Panniculitis}

First described in 1924, clinically-apparent DM-associated panniculitis, defined as inflammation of the subcutaneous 
fat, is considered a rare manifestation that has been reported in about 30 adult and juvenile DM patients (7-11). However, subclinical panniculitis has been described in up to $10 \%$ of cases and thus, may occur more frequently than initially thought (12-15). It appears as tender, indurated, erythematous nodules and plaques on the proximal extremities and/or abdomen typically with sparing of the face $(10,14,16,17)$. Ulceration, lipoatrophy, and calcinosis may also be present $(8,13,18,19)$. Temporally, it can develop prior to, simultaneously with, or after the diagnosis of DM $(10,19)$. Histopathologically, it appears as a lobular panniculitis with lymphocytic and plasma cell infiltrates often accompanied by the characteristic epidermal and dermal changes found in DM, namely vacuolar interface dermatitis and mucin deposition $(16,20)$. Of note, the histopathology of panniculitis in DM is virtually identical to that of lupus panniculitis in the absence of overlying epidermal changes of discoid lupus erythematous, and as such, correlation with other clinical attributes such as anatomic distribution of lesions and concurrent symptomatology are required to distinguish between the two entities $(20,21)$. An association with various solid malignancies was reported in six cases of adult DM and with the anti-melanoma differentiation associated gene 5 protein (MDA5) antibody in a large Mediterranean cohort (OR: 3.85, 95\% CI: 1.11-13.27, $\mathrm{P}<0.05)(18,22)$. In one case series, four out of 18 showed positivity for anti-Mi-2, two for anti-small ubiquitin-like modifier-activating enzyme (SAE), and one each for anti-transcription intermediary factor 1-gamma (TIF-1-gamma), anti-nuclear matrix protein-2 (NXP2), and anti-ribonucleoprotein (RNP) (20).

The approach to treatment is the same for classic DM with high-dose systemic corticosteroids constituting first line treatment and refractory cases managed with pulsedose steroids, methotrexate, azathioprine, cyclosporine, mycophenolate mofetil, cyclophosphamide, and/or intravenous immunoglobulin (IVIG) $(2,5)$. In general; however, DM patients with panniculitis have been found to be responsive to treatment, which suggests that presence of panniculitis may portend a good prognosis based upon limited case reports $(19,23)$.

\section{Diffuse subcutaneous edema}

While periorbital and focal/localized subcutaneous edema especially in poikilodermatous sites is a common feature of DM, more widespread edema, sometimes to the point of anasarca, is considerably rare (24-29). To date, only 20 or so cases involving juvenile and adult patients with DM presenting with diffuse limb, trunk, and/or generalized subcutaneous edema have been reported in the literature since it was first described by Nitsche in 1988 (24,30-38). Most cases are idiopathic but an associated malignancy has been reported in a few $(28,32,36,38)$. Onset can precede, accompany, or follow the diagnosis of DM. The mechanism for this more intense form of edema that exceeds that seen in typical DM is unclear; a hypothesis is that it represents excessive vascular permeability and subsequent leakage as a consequence of immune complex deposition $(25,31,39)$. This more severe form of subcutaneous edema is not clearly correlated with autoantibody status, although subcutaneous edema defined as pitting or non-pitting extremity edema accompanying the active phase of the disease has been found to occur more often in anti-NXP-2 positive than in anti-NXP-2 negative patients ( $36 \%$ vs. 19\%, $\mathrm{P}=0.01$ ) (40). Histopathology is non-specific and shows findings typical for DM. Fat-suppressed T2-weighted and/or short $\tau$ inversion-recovery (STIR) magnetic resonance imaging (MRI) has been found to be useful in identifying the extent of the subcutaneous and muscle edema and in monitoring treatment response (24-26,35). Presence of subcutaneous edema may indicate a more severe form of DM that requires more aggressive management and may carry a worse overall prognosis $(24,26,31)$. In many cases, pulse dose steroids and/or IVIG was required to gain control of the disease (24-28,32).

\section{Erythroderma}

Erythroderma, also referred to as exfoliative dermatitis, is a rare, potentially life-threatening condition characterized by diffuse erythema and scaling involving more than $80-90 \%$ of the body surface area $(41,42)$. A pre-existing dermatosis, most commonly psoriasis or atopic dermatitis, is the most common cause of erythroderma; however, about $20 \%$ of cases remain idiopathic (41-46). Autoimmune connective tissue diseases as a group are considered an uncommon cause of erythroderma, with DM even less so. To date, less than 10 cases of DM-associated erythroderma have been reported, mostly in adults, with some occurring as a paraneoplastic syndrome accompanying a gastric or hepatobiliary malignancy (47-55). Erythroderma can be the presenting feature that eventually leads to the diagnosis of DM or can occur concomitantly or after the diagnosis of DM. The histopathology is non-specific and includes the findings typical for DM, specifically vacuolar interface 
change, papillary dermal edema, and a dermal perivascular lymphocytic infiltration (49). There is no clear relationship with autoantibody status; anti-Mi-2 was positive in one case and TIF-1-gamma in another case associated with gastric adenocarcinoma $(48,51)$. Treatment is the same as for classic DM and, if occurring as a paraneoplastic syndrome, involves addressing the concomitant malignancy.

\section{Calcinosis}

Calcinosis, or the dystrophic deposition of calcium salts (specifically carbonate apatite) in the skin and soft tissues, is a well-recognized feature of juvenile DM, occurring in about $40 \%$ of JDM patients (56-58). However, it is only about half as common in adults, with a prevalence of about $20 \%$ and tends to occur later in the disease course $(59,60)$. DM-associated calcinosis can be categorized into four overlapping types-calcinosis circumscripta, which appears as superficial, discrete papules or nodules on the skin and around joints; tumoral calcinosis, which occurs deeper in the dermis, subcutaneous tissue, muscle, and/or fascia; deposits along the myofascial planes known a calcinosis universalis; or an extensive, generalized form known as exoskeletal calcinosis $(56,57,61-63)$. The lesions may be associated with significant pain and discomfort, particularly if concomitant ulceration, panniculitis, and secondary infection occur (56). The distribution of DM-associated calcinosis is somewhat distinct from that of systemic sclerosis in that lesions prominently occur not only on the extremities, but also on the trunk $(59,64)$. More so, calcinosis can develop on virtually any site, including the face and jaw $(59,65,66)$. An association between the presence of anti-NXP-2 antibody and presence and severity of calcinosis is well-established in both juvenile and adult DM patients (40,67-69). On biopsy, calcinosis cutis appear as largely acellular calcium deposits in the skin and subcutaneous tissue that stain with von Kossa silver stain or Alizarin red (70). Plain radiographs may also be useful to determine the pattern, depth, and spread of calcinosis (71). Treatment remains challenging and no guidelines exist for selecting the best initial regimen. Several classes of drugs have been used in various combinations. Anti-inflammatory medications such as IVIG, systemic and intralesional steroids, infliximab, abatacept, rituximab, colchicine, minocycline, and thalidomide have been employed with varying degrees of success. Another approach includes the use of medications that influence serum calcium and phosphate levels such as diltiazem, bisphosphonates, probenecid, aluminum hydroxide, warfarin, and intradermal, intralesional, or intravenous sodium thiosulfate. Surgical removal of calcinotic nodules is an option for those with more contained, limited forms of the disease $(59,72)$.

\section{Ulcers}

One of the most widely substantiated clinical and autoantibody correlations in adult (but not juvenile) patients with DM is that between cutaneous ulcers and anti-MDA5 antibody positivity, with odds ratios ranging from 10 to 18 in some cohorts (73-75). The other features that characterize anti-MDA5 disease include clinically amyopathic DM, rapidly-progressive interstitial lung disease, and painful palmar papules $(73,74,76,77)$. However, the relationship between skin ulcers and anti-MDA5 positivity is not exclusive as it has also been observed in DM patients harboring other myositis-specific and myositisassociated antibodies (73). Ulceration in DM patients can occur in various locations such as the elbows, knees, and trunk; however, several sites such as the digital pulp, periungual areas, and the skin overlying Gottron's papules are more specific for the anti-MDA5-associated phenotype $(73,74,78,79)$. The ulcers develop as a consequence of multiple, varied pathologic processes such as mechanical trauma, calcinosis, and immune-mediated vascular damage; in patients with anti-MDA5 positivity, it is largely attributed to profound vasculopathy induced by a high type1 interferon signature $(74,80)$. Independent of whether or not it occurs in the context of anti-MDA5 positive disease, the presence of ulcers has been linked to a more severe disease course in both adult and juvenile DM patients that is punctuated by frequent flares and an increased incidence of complications such as serious infections (gangrene, osteomyelitis), extensive tissue necrosis, and/or systemic ulcerative disease and thus, is largely considered an adverse prognostic factor $(73,74,81-83)$. A significant correlation between ulceration (typically with accompanying cutaneous necrosis) and malignancy has also been described in several European cohorts (84-86), although not in a United States-based cohort (73). There are no established ulcerdirected therapies but cyclophosphamide, cyclosporine, and azathioprine with or without steroids have been shown to be effective in several case reports $(74,82,87-89)$. Most patients, however, will require multiple immunomodulatory drugs in the DM armamentarium such as pulse- or highdose steroids, IVIG, and other disease-modifying antirheumatic drugs (DMARDs). Medications that aim to offset 


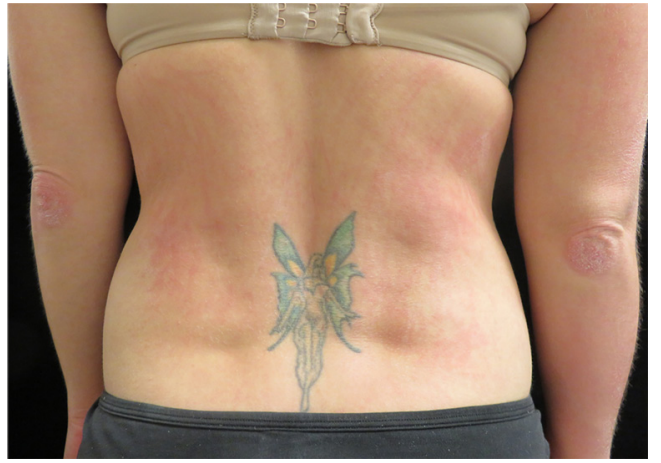

Figure 1 Flagellate erythema. Streak-like erythematous eruption on the arms and mid- to lower back of a patient with DM. DM, dermatomyositis.

the vasculopathy in MDA5-positive patients by improving blood flow (e.g., antiplatelets and calcium channel blockers) have been used with mixed results $(74,78)$.

\section{Flagellate erythema}

As the name implies, flagellate erythema is a linear, lacy, streak-like erythematous eruption of macules, papules, and/or plaques on the skin accompanied by pruritus or pain (Figure 1) $(90,91)$. Initially described as a distinct side effect of bleomycin exposure, it has since been reported to arise in conjunction with a host of other agents and conditions, including DM (90-101). It is considered a rare manifestation of DM, observed in only $5 \%$ of patients in one cohort, and has been noted to occur both prior to and in tandem with the other classic cutaneous signs (101). Only two cases have been reported in juvenile patients to date with the vast majority occurring in adults $(97,102)$. Compared to its bleomycin-induced counterpart which is said to be more brownish in appearance, the flagellate erythema seen with DM is said to be more erythematous, a finding reflective of the higher degree of inflammation $(96,98)$. Histopathologic information derived from 4 cases revealed the typical DM findings of interface dermatitis with a perivascular lymphocytic infiltrate $(52,95,102,103)$. There are no clear phenotypic or antibody associations nor prognostic implications; a positive anti-MDA5 and a positive anti-TIF-1 were noted in 1 case each and concomitant malignancy in 3 cases $(95,99,104,105)$. In contrast to the other cutaneous lesions of DM, flagellate erythema can resolve spontaneously; however, treatment of the other manifestations of DM is still required $(90,99)$.

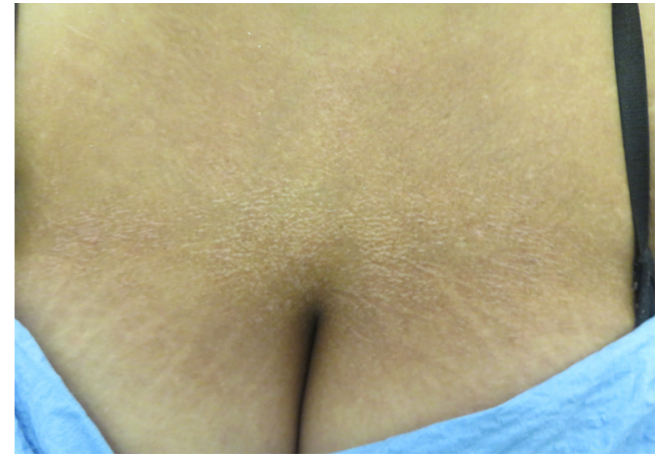

Figure 2 Wong-type dermatomyositis. Pinkish, hyperkeratotic, follicular papules with "islands of sparing" in the lumbosacral area.

\section{Wong-type DM}

First described in the 1960s by a Hong Kong-based physician after whom it was eventually named, Wongtype $\mathrm{DM}$ is a rare variant in which DM clinically and histopathologically overlaps with pityriasis rubra pilaris (PRP), a chronic inflammatory papulosquamous disorder characterized by reddish-orange, variably-sized plaques and follicular papules with intervening areas of unaffected skin known as "islands of sparing" (Figure 2) $(106,107)$. To date, there are fewer than 30 reported cases of Wong-type DM in both children and adults (108-114). An association with malignancy was seen in half of the original cohort reported by Wong; however, subsequent reports have not validated this association. Thus, it is unclear whether having the Wong-type phenotype of DM increases the risk of malignancy in excess of what would be expected with classic DM (115). Clinically, Wong-type DM presents with a combination of classic cutaneous DM features such as the heliotrope eruption, Gottron's papules, and poikiloderma alongside the typical reddish-orange confluent papules and plaques that characterize PRP. Hyperkeratosis of the palms and soles is often present. Histopathologically, an overlap between the two disease entities is likewise observed, with vacuolar interface alterations and abundant dermal mucin occurring with alternating mounds of para- and orthokeratosis and follicular plugging $(115,116)$. Onset of PRP varies and can occur prior to, simultaneously with, or after the diagnosis of DM. There is no consistent correlation with autoantibody status; one case was positive for anti-MDA5 (111). Treatment is typically directed at DM rather than PRP and consists of corticosteroids and the 
Page 6 of 11

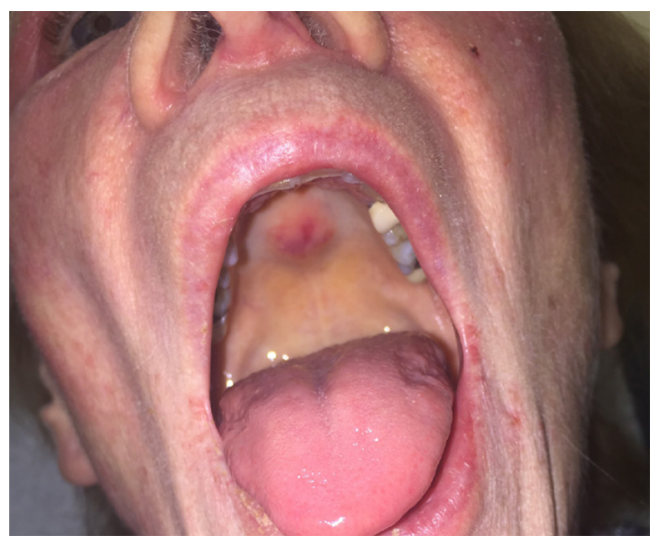

Figure 3 Ovoid palatal patch. Well-defined, ovoid, non-ulcerative erythematous patch on the posterior hard palate.

steroid-sparing DMARDs, with good musculocutaneous response in the majority of patients $(115,116)$. Retinoids, which are used to treat PRP, have anecdotally been used in this context, but there is a lack of literature regarding this class of medications for this entity.

\section{Gingival telangiectasias}

Telangiectasias on the skin (in the setting of poikiloderma) and of the nail fold capillaries are well-known features of $\operatorname{DM}(6,117)$. However, telangiectasias can also present in the gingival and oral mucosa, a finding that mirrors antibodymediated vasculopathy seen in DM and can serve an important diagnostic role in JDM (118-120). This finding has been described in both juvenile and adult patients, with one case series reporting a prevalence of $20 \%$ in adult DM patients (121). Recurrent, refractory gum bleeding is the usual presenting symptom. Gingival telangiectasias typically occur with other overt musculocutaneous signs of DM but in two cases, were found to develop a few weeks prior, highlighting their role in facilitating early diagnosis in these rare circumstances $(118,122)$. Treatment is the same as for classic DM; additionally, a referral to a periodontist may also be warranted, especially for those with persistent bleeding and discomfort.

\section{Ovoid palatal patch}

Another intraoral lesion that has been observed in DM is the ovoid palatal patch. Appearing as a well-defined, arcuate, non-ulcerative erythematous patch on the posterior hard palate, it is strongly associated with the presence of

\section{Castillo and Femia. Cutaneous manifestations of dermatomyositis}

TIF-1-gamma antibodies and with malignancy (Figure 3) (123-125). Biopsy of the patch is consistent with the typical DM findings. The approach to therapy is the same as for classic DM with emphasis on a thorough work-up for malignancy.

\section{Conclusions}

While the majority of patients with DM will present with hallmark or characteristic cutaneous, muscular, and systemic and systemic symptoms, for those in whom the clinical picture is less straight forward, recognition of nonhallmark cutaneous findings may be particularly crucial. In a disease such as DM that is strikingly heterogenous and that is associated with such dire conditions as malignancy and rapidly-progressive interstitial lung disease, timely diagnosis and early intervention is unquestionably of paramount importance. Dermatologists, rheumatologists, and healthcare providers should thus remain cognizant of these cutaneous clues, however covert, in order to facilitate the diagnostic process and subsequently improve overall patient outcomes.

\section{Acknowledgments}

Funding: None.

\section{Footnote}

Provenance and Peer Review: This article was commissioned by the Guest Editors (Drs. Richard D. Sontheimer, M. Kari Connolly, David F. Fiorentino, and Victoria P. Werth) for the series "Rheumatologic Skin Disease" published in Annals of Translational Medicine. The article has undergone external peer review.

Conflicts of Interest: Both authors have completed the ICMJE uniform disclosure form (available at http://dx.doi. org/10.21037/atm-20-5252). The series "Rheumatologic Skin Disease" was commissioned by the editorial office without any funding or sponsorship. ANF reports personal fees from Octagon Therapeutics, outside the submitted work. The authors have no other conflicts of interest to declare.

Ethical Statement: The authors are accountable for all aspects of the work in ensuring that questions related to the accuracy or integrity of any part of the work are 
appropriately investigated and resolved.

Open Access Statement: This is an Open Access article distributed in accordance with the Creative Commons Attribution-NonCommercial-NoDerivs 4.0 International License (CC BY-NC-ND 4.0), which permits the noncommercial replication and distribution of the article with the strict proviso that no changes or edits are made and the original work is properly cited (including links to both the formal publication through the relevant DOI and the license). See: https://creativecommons.org/licenses/by-nc-nd/4.0/.

\section{References}

1. Bohan A, Peter JB. Polymyositis and Dermatomyositis. N Engl J Med 1975;292:344-7.

2. Aggarwal R, Rider LG, Ruperto N, et al. 2016 American College of Rheumatology/European League Against Rheumatism criteria for minimal, moderate, and major clinical response in adult dermatomyositis and polymyositis: An International Myositis Assessment and Clinical Studies Group/Paediatric Rheumatology International Trials Organisation Collaborative Initiative. Ann Rheum Dis 2017;76:792-801.

3. Sontheimer RD. Would a new name hasten the acceptance of amyopathic dermatomyositis (dermatomyositis siné myositis) as a distinctive subset within the idiopathic inflammatory dermatomyopathies spectrum of clinical illness? J Am Acad Dermatol 2002;46:626-36.

4. Gerami P, Schope JM, McDonald L, et al. A systematic review of adult-onset clinically amyopathic dermatomyositis (dermatomyositis siné myositis): a missing link within the spectrum of the idiopathic inflammatory myopathies. J Am Acad Dermatol 2006;54:597-613.

5. Femia AN, Vleugels RA, Callen JP. Cutaneous Dermatomyositis: An Updated Review of Treatment Options and Internal Associations. Am J Clin Dermatol 2013;14:291-313.

6. Concha JSS, Pena S, Gaffney RG, et al. Developing classification criteria for skin-predominant dermatomyositis: the Delphi process. Br J Dermatol 2020;182:410-7.

7. Parkes Weber F, Gray AMH. Chronic Relapsing Polydermatomyositis with Predominant Involvement of the Subcutaneous Fat (Panniculitis). Br J Dermatol 1924;36:544-60.

8. Solans R, Corteés J, Selva A, et al. Panniculitis: A cutaneous manifestation of dermatomyositis. J Am Acad
Dermatol 2002;46:S148-50.

9. Carroll M, Mellick N, Wagner G. Dermatomyositis panniculitis: a case report. Australas J Dermatol 2015;56:224-6.

10. Salman A, Kasapcopur O, Ergun T, et al. Panniculitis in juvenile dermatomyositis: Report of a case and review of the published work. J Dermatol 2016;43:951-3.

11. Braunstein I, Werth VP. Update on management of connective tissue panniculitides. Dermatol Ther 2012;25:173-82.

12. Janis JF, Winkelmann RK. Histopathology of the Skin in Dermatomyositis: A Histopathologic Study of 55 Cases. Arch Dermatol 1968;97:640-50.

13. Chao YY, Yang LJ. Dermatomyositis presenting as panniculitis. Int J Dermatol 2000;39:141-4.

14. Ghali FE, Reed AM, Groben PA, et al. Panniculitis in juvenile dermatomyositis. Pediatr Dermatol 1999;16:270-2.

15. Wainger CK, Lever WF. Dermatomyositis: Report of Three Cases with Postmortem Observations. Arch Derm Syphilol 1949;59:196-208.

16. Kuhn A. Characterizing clinicopathological and immunohistochemical findings in dermatomyositis panniculitis. J Eur Acad Dermatol Venereol 2018;32:1231-2.

17. Hattori $Y$, Matsuyama K, Takahashi T, et al. Anti-MDA5 Antibody-Positive Dermatomyositis Presenting with Cellulitis-Like Erythema on the Mandible as an Initial Symptom. Case Rep Dermatol 2018;10:110-4.

18. Chairatchaneeboon M, Kulthanan K, Manapajon A. Calcific panniculitis and nasopharyngeal cancer-associated adult-onset dermatomyositis: a case report and literature review. Springerplus 2015;4:201.

19. Carneiro S, Alvim G, Resende P, et al. Dermatomyositis with panniculitis. Skinmed 2007;6:46-7.

20. Santos-Briz A, Calle A, Linos K, et al. Dermatomyositis panniculitis: a clinicopathological and immunohistochemical study of 18 cases. J Eur Acad Dermatol Venereol 2018;32:1352-9.

21. Hansen CB, Callen JP. Connective tissue panniculitis: lupus panniculitis, dermatomyositis, morphea/scleroderma. Dermatol Ther 2010;23:341-9.

22. Labrador-Horrillo M, Martinez MA, Selva-O'Callaghan A, et al. Anti-MDA5 antibodies in a large Mediterranean population of adults with dermatomyositis. J Immunol Res 2014;2014:290797.

23. Azevedo PO, Castellen NR, Salai AF, et al. Panniculitis associated with amyopathic dermatomyositis. An Bras 
Dermatol 2018;93:119-21.

24. Shukla M, Patel R, Kuzyshyn H, et al. Subcutaneous oedema of upper limbs heralding an aggressive form of dermatomyositis. BMJ Case Rep 2018;2018:bcr2017221908.

25. Karabiber H, Aslan M, Alkan A, et al. A rare complication of generalized edema in juvenile dermatomyositis: a report of one case. Brain Dev 2004;26:269-72.

26. Chai Y, Bertorini TE, Li YD, et al. Limb edema and anasarca associated with severe dermatomyositis: report of four cases. Neuromuscul Disord 2011;21:439-42.

27. Jung KD, Kim PS, Park HY, et al. Dermatomyositis associated with generalized subcutaneous edema and Evans syndrome. J Am Acad Dermatol 2012;66:144-7.

28. Milisenda JC, Doti PI, Prieto-González S, et al. Dermatomyositis presenting with severe subcutaneous edema: five additional cases and review of the literature. Semin Arthritis Rheum 2014;44:228-33.

29. Werner de Castro GR, Appenzeller S, Bértolo MB, et al. Acute dermatomyositis with subcutaneous generalized edema. Clin Rheumatol 2006;25:898-900.

30. Nitsche A, San Agustín PG, Amado V, et al. Trunk and abdominal wall edema in dermatomyositis. Medicina (B Aires) 1988;48:331-2.

31. Tu J, McLean-Tooke A, Junckerstorff R. Increasing recognition of dermatomyositis with subcutaneous edema - is this a poorer prognostic marker? Dermatol Online J 2014;20:21244.

32. Zarrabi K, Choy T, Sweeney K, et al. Paraneoplastic edematous dermatomyositis: A rare syndrome observed in a case of small cell lung cancer. Clin Pract 2017;7:982.

33. Shelley BP, Chakraborti S. A viral polymyositis masquerade: Life-threatening case of juvenile dermatomyositis complicated by systemic capillary leak syndrome. Ann Indian Acad Neurol 2018;21:70-4.

34. Chandrakasan S, Singh S, Ratho RK, et al. Anasarca as the presenting manifestation of parvovirus B19 associated juvenile dermatomyositis. Rheumatol Int 2009;29:565-7.

35. Lee KH, Lim SR, Kim YJ, et al. Acute dermatomyositis associated with generalized subcutaneous edema. Rheumatol Int 2008;28:797-800.

36. Gorelik O, Almoznino-Sarafian D, Alon I, et al. Acute inflammatory myopathy with severe subcutaneous edema, a new variant? Report of two cases and review of the literature. Rheumatol Int 2001;20:163-6.

37. Mroué KH, Sharara NH, Rbeiz JG, et al. A case of edematous dermatomyositis. J Rheumatol 2003;30:2722-3.

38. Smyth AE, Bell AL, Crone M. Acute oedematous dermatomyositis. Ann Rheum Dis 2000;59:575.

39. Saygi S, Alehan F, Baskin E, et al. Juvenile dermatomyositis presenting with anasarca. J Child Neurol 2008;23:1353-6.

40. Albayda J, Pinal-Fernandez I, Huang W, et al. Antinuclear Matrix Protein 2 Autoantibodies and Edema, Muscle Disease, and Malignancy Risk in Dermatomyositis Patients. Arthritis Care Res (Hoboken) 2017;69:1771-6.

41. Miyashiro D, Sanches JA. Erythroderma: a prospective study of 309 patients followed for 12 years in a tertiary center. Sci Rep 2020;10:9774.

42. Pal S, Haroon TS. Erythroderma: A clinico-etiologic study of 90 cases. Int J Dermatol 1998;37:104-7.

43. Gudjonsson JE, Elder JT. Chapter 18. Psoriasis. In: Goldsmith LA, Katz SI, Gilchrest BA, et al., editors. Fitzpatrick's Dermatology in General Medicine, 8 ed. New York, NY: The McGraw-Hill Companies, 2012.

44. Yuan XY, Guo JY, Dang YP, et al. Erythroderma: A clinical-etiological study of 82 cases. Eur J Dermatol 2010;20:373-7.

45. Li J, Zheng H-Y. Erythroderma: a clinical and prognostic study. Dermatology 2012;225:154-62.

46. César A, Cruz M, Mota A, et al. Erythroderma. A clinical and etiological study of 103 patients. J Dermatol Case Rep 2016;10:1-9.

47. Herath HMMTB, Keragala BSDP, Pahalagamage SP, et al. Erythroderma and extensive poikiloderma - a rare initial presentation of dermatomyositis: a case report. J Med Case Rep 2018;12:83.

48. Brickman ZJ, Coomes EA, Stroud L. Erythrodermic paraneoplastic dermatomyositis. CMAJ 2018;190:E1453.

49. Kim SW, Kang YS, Park SH, et al. A case of erythrodermic dermatomyositis associated with gastric cancer. Ann Dermatol 2009;21:435-9.

50. Ge W, Teng B-W, Yu D-C, et al. Dermatosis as the initial presentation of gastric cancer: two cases. Chin J Cancer Res 2014;26:632-8.

51. Valdés-González G, Chávez-López M, Gallaga-Gutiérrez A, et al. Dermatomyositis-erythrodermia: clinical presentation not associated to malignancy. A case report. Reumatol Clin 2014;10:48-50.

52. Nousari HC, Kimyai-Asadi A, Spegman DJ. Paraneoplastic dermatomyositis presenting as erythroderma. J Am Acad Dermatol 1998;39:653-4.

53. Chander R, Gupta T, Rani S, et al. Erythrodermic juvenile dermatomyositis. Pediatr Dermatol 2009;26:234-5.

54. Miyagawa S, Okazaki A, Minowa R, et al. Dermatomyositis presenting as erythroderma. J Am Acad Dermatol 1992;26:489-90. 
55. Liu ZH, Wang XD. Acute-onset adult dermatomyositis presenting with erythroderma and diplopia. Clin Exp Dermatol 2007;32:751-2.

56. Hoeltzel MF, Oberle EJ, Robinson AB, et al. The presentation, assessment, pathogenesis, and treatment of calcinosis in juvenile dermatomyositis. Curr Rheumatol Rep 2014;16:467.

57. Orandi AB, Baszis KW, Dharnidharka VR, et al. Assessment, classification and treatment of calcinosis as a complication of juvenile dermatomyositis: a survey of pediatric rheumatologists by the childhood arthritis and rheumatology research alliance (CARRA). Pediatr Rheumatol Online J 2017; 15:71.

58. Eidelman N, Boyde A, Bushby AJ, et al. Microstructure and mineral composition of dystrophic calcification associated with the idiopathic inflammatory myopathies. Arthritis Res Ther 2009;11:R159.

59. Balin SJ, Wetter DA, Andersen LK, et al. Calcinosis cutis occurring in association with autoimmune connective tissue disease: The Mayo Clinic experience with 78 patients, 1996-2009. Arch Dermatol 2012;148:455-62.

60. Valenzuela A, Chung L, Casciola-Rosen L, et al. Identification of clinical features and autoantibodies associated with calcinosis in dermatomyositis. JAMA Dermatology 2014;150:724-9.

61. Blane CE, White SJ, Braunstein EM, et al. Patterns of calcification in childhood dermatomyositis. AJR Am J Roentgenol 1984;142:397-400.

62. Sanyal S, Atwal SS, Mondal D, et al. Radiographic Patterns of Soft Tissue Calcinosis in Juvenile Dermatomyositis and its Clinical Implications. J Clin Diagn Res 2014;8:RD08.

63. Chung MP, Richardson C, Kirakossian D, et al. Calcinosis Biomarkers in Adult and Juvenile Dermatomyositis. Autoimmun Rev 2020;19:102533.

64. Gutierrez Jr A, Wetter DA. Calcinosis cutis in autoimmune connective tissue diseases. Dermatol Ther 2012;25:195-206.

65. Fava A, Christopher-Stine L. Calcinosis of the Mandible in Dermatomyositis. Arthritis Rheumatol 2018;70:1353.

66. Walsh JS, Fairley JA. Calcifying disorders of the skin. J Am Acad Dermatol 1995;33:693-706.

67. Rogers A, Chung L, Li S, et al. Cutaneous and Systemic Findings Associated With Nuclear Matrix Protein 2 Antibodies in Adult Dermatomyositis Patients. Arthritis Care Res (Hoboken) 2017;69:1909-14.

68. Tansley SL, Betteridge ZE, Shaddick G, et al. Calcinosis in juvenile dermatomyositis is influenced by both antiNXP2 autoantibody status and age at disease onset.
Rheumatology (Oxford) 2014;53:2204-8.

69. Gunawardena H, Wedderburn LR, Chinoy H, et al. Autoantibodies to a $140-\mathrm{kd}$ protein in juvenile dermatomyositis are associated with calcinosis. Arthritis Rheum 2009;60:1807-14.

70. Mochel MC, Arakaki RY, Wang G, et al. Cutaneous calciphylaxis: A retrospective histopathologic evaluation. Am J Dermatopathol 2013;35:582-6.

71. Shahi V, Wetter DA, Howe BM, et al. Plain radiography is effective for the detection of calcinosis cutis occurring in association with autoimmune connective tissue disease. $\mathrm{Br}$ J Dermatol 2014;170:1073-9.

72. Mendelson BC, Linscheid RL, Dobyns JH, et al. Surgical treatment of calcinosis cutis in the upper extremity. J Hand Surg Am 1977;2:318-24.

73. Narang NS, Casciola-Rosen L, Li S, et al. Cutaneous ulceration in dermatomyositis: Association with antimelanoma differentiation-associated gene 5 antibodies and interstitial lung disease. Arthritis Care Res (Hoboken) 2015;67:667-72.

74. Fiorentino D, Chung L, Zwerner J, et al. The mucocutaneous and systemic phenotype of dermatomyositis patients with antibodies to MDA5 (CADM-140): A retrospective study. J Am Acad Dermatol 2011;65:25-34.

75. Devaux CA, Rolain J-M, Colson P, et al. New insights on the antiviral effects of chloroquine against coronavirus: what to expect for COVID-19? Int J Antimicrob Agents 2020;55;105938.

76. Moghadam-Kia S, Oddis CV, Sato S, et al. Antimelanoma Differentiation-associated Gene 5 Antibody: Expanding the Clinical Spectrum in North American Patients with Dermatomyositis. J Rheumatol 2017;44:319-25.

77. Kurtzman DJB, Vleugels RA. Anti-melanoma differentiation-associated gene 5 (MDA5) dermatomyositis: A concise review with an emphasis on distinctive clinical features. J Am Acad Dermatol 2018;78:776-85.

78. Charrow A, Vleugels RA. Cutaneous Ulcerations in AntiMDA5 Dermatomyositis. N Engl J Med 2019;381:465.

79. Cao H, Xia Q, Pan M, et al. Gottron papules and gottron sign with ulceration: A distinctive cutaneous feature in a subset of patients with classic dermatomyositis and clinically amyopathic dermatomyositis. J Rheumatol 2016;43:1735-42.

80. Ono N, Kai K, Maruyama A, et al. The relationship between type 1 IFN and vasculopathy in anti-MDA5 antibody-positive dermatomyositis patients. Rheumatology 
(Oxford) 2019;58:786-91.

81. Gupta A, Pilania RK, Singh S. Symmetrical cutaneous ulcers: Are they associated with severe disease in children with juvenile dermatomyositis? Eur J Rheumatol 2019;7:50-1.

82. Gupta A, Pilania RK, Prasad VD, et al. Extensive skin ulcers in a child with juvenile dermatomyositis. BMJ Case Rep 2018;2018:bcr2017222915.

83. Gennaro AR, Bacon HE. Dermatomyositis and associated lesions of the gastrointestinal tract. Dis Colon Rectum 1969;12:256-60.

84. Burnouf M, Mahé E, Verpillat P, et al. Cutaneous necrosis is predictive of cancer in adult dermatomyositis. Ann Dermatol Venereol 2003;130:313-6.

85. Prohic A, Kasumagic-Halilovic E, Simic D, et al. Clinical and biological factors predictive of malignancy in dermatomyositis. J Eur Acad Dermatol Venereol 2009;23:591-2.

86. Ponyi A, Constantin T, Garami M, et al. Cancer-associated myositis: Clinical features and prognostic signs. Ann N Y Acad Sci 2005;1051:64-71.

87. Tsujimura S, Saito K, Tanaka Y. Complete resolution of dermatomyositis with refractory cutaneous vasculitis by intravenous cyclophosphamide pulse therapy. Intern Med 2008;47:1935-40.

88. Nagashima T, Nakamura J, Iwamoto M, et al. Deep cutaneous ulcers in dermatomyositis. Intern Med 2017;56:1749-50.

89. Shimojima $Y$, Ishii $W$, Kato $T$, et al. Intractable skin necrosis and interstitial pneumonia in amyopathic dermatomyositis, successfully treated with cyclosporin A. Intern Med 2003;42:1253-8.

90. Jara M, Amérigo J, Duce S, et al. Dermatomyositis and flagellate erythema. Clin Exp Dermatol 1996;21:440-1.

91. Bhushan P, Manjul P, Baliyan V. Flagellate dermatoses. Indian J Dermatol Venereol Leprol 2014;80:149-52.

92. Cohen PR. Trastuzumab-Associated Flagellate Erythema: Report in a Woman with Metastatic Breast Cancer and Review of Antineoplastic Therapy-Induced Flagellate Dermatoses. Dermatol Ther (Heidelb) 2015;5:253-64.

93. Moulin G, Fière B, Beyvin A. Cutaneous pigmentation caused by bleomycin. Bull Soc Fr Dermatol Syphiligr 1970;77:293-6.

94. Nousari HC, Ha VT, Laman SD, et al. "Centripetal flagellate erythema": a cutaneous manifestation associated with dermatomyositis. J Rheumatol 1999;26:692-5.

95. Molina-Ruiz AM, Romero F, Carrasco L, et al. Amyophatic dermatomyositis presenting as a flagellated skin eruption with positive MDA5 antibodies and thyroid cancer: A real association? Clin Exp Dermatol 2015;40:887-90.

96. Yamamoto T, Nishioka K. Flagellate erythema. Int J Dermatol 2006;45:627-31.

97. Eichenfield DZ, Paravar T. Zebra Stripes in Dermatomyositis: Case Report and Review of Flagellate Erythema-Associated Dermatomyositis. J Eur Acad Dermatol Venereol 2017;31:e7-9.

98. Mai S, Mansouri S, Benzekri L, et al. Severe flagellate erythema in idiopathic dermatomyositis. BMJ Case Rep 2019;12:e232785.

99. Manriquez J, Acle R, Llanos C. Flagellate Erythema in a Case of Paraneoplastic Dermatomyositis. J Clin Rheumatol 2016;22:435.

100. Watanabe T, Tsuchida T. "Flagellate" erythema in dermatomyositis. Dermatology 1995;190:230-1.

101. Parodi A, Caproni M, Marzano AV, et al. Dermatomyositis in 132 patients with different clinical subtypes: Cutaneous signs, constitutional symptoms and circulating antibodies. Acta Derm Venereol 2002;82:48-51.

102.Hew C, Solman L, Taylor G, et al. G454(P) Flagellate erythema associated with juvenile dermatomyositis. Arch Dis Child 2018;103:A186.

103. Gorouhi F, Kiuru M, Silverstein M, et al. The pulseless patient: Profound vasculopathy as the presenting feature of fulminant dermatomyositis and response to therapy. JAAD Case Rep 2019;5:176-9.

104. Requena C, Alfaro A, Traves V, et al. Paraneoplastic Dermatomyositis: A Study of 12 Cases. Actas DermoSifiliográficas 2014;105:675-82.

105. Ito K, Imafuku S, Hamaguchi Y, et al. Case report of antitranscription intermediary factor- $1-\gamma / \alpha$ antibody-positive dermatomyositis associated with gastric cancer and immunoglobulin G4-positive pulmonary inflammatory pseudotumor. J Dermatol 2013;40:567-9.

106. Brown F, Badri T. Pityriasis Rubra Pilaris. Treasure Island (FL): StatPearls Publishing, 2020.

107. Wong KO. Dermatomyositis: a clinical investigation of twenty-three cases in Hong Kong. Br J Dermatol 1969;81:544-7.

108. Requena L, Grilli R, Soriano L, et al. Dermatomyositis with a pityriasis rubra pilaris-like eruption: a little-known distinctive cutaneous manifestation of dermatomyositis. $\mathrm{Br}$ J Dermatol 1997;136:768-71.

109. Polat M, Lenk N, Ustün H, et al. Dermatomyositis with a pityriasis rubra pilaris-like eruption: an uncommon cutaneous manifestation in dermatomyositis. Pediatr Dermatol 2007;24:151-4. 
110.Didona D, Fania L, Didona B. Wong-type dermatomyositis. G Ital Dermatol Venereol 2018;153:115-6.

111. Canavan T, Sidorsky T, Doan LT, et al. A case of Wongtype dermatomyositis with concomitant anti-MDA5 features. J Am Acad Dermatol 2014;70:e62-4.

112.Yu WY, North JP, McCalmont TH, et al. Wong-type dermatomyositis during anti-PD-1 therapy. JAAD Case Reports 2018;4:1049-51.

113. Beckum KM, Gavino ACP, Marks S, et al. Wong type dermatomyositis: 20th case reported. J Drugs Dermatol 2010;9:1475-6.

114. Diplomatico M, Ametrano O, Errico ME, et al. WongType Dermatomyositis: An Extremely Rare Disease in Childhood. Dermatol Pract Concept 2019;9:325-6.

115.Mutasim DF, Egesi A, Spicknall KE. Wong-type dermatomyositis: a mimic of many dermatoses. J Cutan Pathol 2016;43:781-6.

116. Umanoff N, Fisher A, Carlson JA. Wong-Type Dermatomyositis Showing Porokeratosis-Like Changes (Columnar Dyskeratosis): A Case Report and Review of the Literature. Dermatopathology (Basel) 2015;2:1-8.

117. Callen JP. Dermatomyositis. Lancet 2000;355:53-7.

118. Ghali FE, Stein LD, Fine JD, et al. Gingival telangiectases: an underappreciated physical sign of juvenile dermatomyositis. Arch Dermatol 1999;135:1370-4.

Cite this article as: Castillo RL, Femia AN. Covert clues: the non-hallmark cutaneous manifestations of dermatomyositis. Ann Transl Med 2021;9(5):436. doi: 10.21037/atm-20-5252
119. Karasawa R, Tamaki M, Sato T, et al. Multiple target autoantigens on endothelial cells identified in juvenile dermatomyositis using proteomics. Rheumatology (Oxford) 2018;57:671-6.

120. Rider LG, Atkinson JC. Images in clinical medicine. Gingival and periungual vasculopathy of juvenile dermatomyositis. N Engl J Med 2009;360:e21.

121. Márton K, Hermann P, Dankó K, et al. Evaluation of oral manifestations and masticatory force in patients with polymyositis and dermatomyositis. J Oral Pathol Med 2005;34:164-9.

122. Gonçalves LM, Bezerra-Júnior JRS, Gordón-Núñez MA, et al. Oral manifestations as important symptoms for juvenile dermatomyositis early diagnosis: a case report. Int J Paediatr Dent 2011;21:77-80.

123. Bernet LL, Lewis MA, Rieger KE, et al. Ovoid Palatal Patch in Dermatomyositis: A Novel Finding Associated With Anti-TIF1 $\gamma$ (p155) Antibodies. JAMA Dermatol 2016;152:1049-51.

124. Bhattacharjee R, Vinay K. Ovoid Palatal Patch: An Ominous Sign in Dermatomyositis. J Clin Rheumatol 2020;26:e80.

125.Franciosi E, Blankenship K, Houk L, et al. Ovoid palatal patch: A clue to anti-TIF1 $\gamma$ dermatomyositis. BMJ Case Rep 2020;13:e234111. 